\section{ORTEGA ARJONILLA, E. (coord.) \\ El paisaje. Percepciones interdisciplinares desde las Humanidades}

\section{Granada: Comares, 2018}

El paisaje es un tema transversal e interdisciplinar. Un concepto poliédrico que aquí está abordado desde diferentes perspectivas, todas ellas permeables que permiten explorar el tema desde diferentes vertientes y disciplinas del conocimiento, mostrando una visión completa que nos permite un acercamiento global.

Las reflexiones que aquí se recogen se vertebran en los siguientes bloques:

El paisaje como objeto de reflexión (o conceptualización) disciplinar e interdisciplinar. De paisajes y paisanajes a lo largo de la historia. Reflexiones lingüísticas y culturales sobre el paisaje propio. Las miradas sobre otro en la percepción del paisaje. Las miradas cruzadas en la percepción del paisaje. Y el paisaje en contexto intersemiótico: adaptación y recreación cinematográfica.

Son un total de veinticinco contribuciones que exploran el concepto de paisaje de manera divergente, desde lo global a lo particular. Reflexiones en torno a diferentes aspectos del término, desde la semiótica y significado, desde una visión histórica, filosófica, geográfica, artística o cinematográfica. Desde la perspectiva del que lo estudia, lo observa, lo lee, lo mira, habita o lo vive. Desde un enfoque personal y desde la indagación sobre el otro o lo otro.

Una exploración completa del término desde diferentes vertientes "por definición, transversales e interdisciplinares, como ocurre en más de una ocasión en las investigaciones que se llevan a cabo dentro del ámbito de las Humanidades" (en palabras del propio coordinador Emilio Ortega).

Esta obra es una aproximación a la complejidad del paisaje y la percepción que desde diferentes disciplinas humanísticas se contempla.

Un concepto estudiado como término, lugar, entorno o medio. Real o construido, vivido en primera persona o estudiado a través de los ojos de otros.

Una obra que permite de una manera amena y cercana una aproximación interdisciplinar, una mirada sobre lo complejo y a la vez cercano que es esta temática. Veinticinco pinceladas que ayudan a construir una visión completa humanista sobre el paisaje, que provocan en el lector múltiples reflexiones y una idea clara sobre la materia propuesta. 
A nivel formal, el coordinador de esta publicación ha conseguido encajar cada aportación para que la obra funcione, superando la dificultad de articulación por la divergencia de los acercamientos propuestos, pero lejos de ser difusa, como pudiese parecer a primera vista por la cantidad de temas que se tratan en torno al paisaje, está organizada para que esta poliédrica visión sea su máxima riqueza.

Las veinticinco personas que reflexionan en torno a esta temática lo hacen desde sus disciplinas de conocimiento, el nexo aglutinador de todos ellas es la Facultad de Filosofía y Letras de la Universidad de Málaga.

Por la tipología de la publicación es una obra de consulta para un primer acercamiento al concepto del paisaje para construir la mirada del lector de una manera integral.

Laura Nogaledo Gómez | Dpto. Escultura e Historia de las Artes Plásticas,

Universidad de Sevilla

URL de la contribución <www.iaph.es/revistaph/index.php/revistaph/article/view/4551> 